\title{
Clinical, demographic and laboratory parameters at HAART initiation associated with decreased post-HAART survival in a U.S. military prospective HIV cohort
}

Alan R Lifson 1,3*, Elizabeth M Krantz ${ }^{2,3}$, Patricia L Grambsch ${ }^{2,3}$, Grace E Macalino ${ }^{3}$, Nancy F Crum-Cianflone ${ }^{3,4}$, Anuradha Ganesan ${ }^{3,5}$, Jason F Okulicz ${ }^{3,6}$, Anne Eaton ${ }^{2}$, John H Powers ${ }^{7}$, Lynn E Eberly ${ }^{2,3}$ and Brian K Agan ${ }^{3^{*}}$, for the Infectious Disease Clinical Research Program HIV/STI Working Group

\begin{abstract}
Background: Although highly active antiretroviral therapy (HAART) has improved HIV survival, some patients receiving therapy are still dying. This analysis was conducted to identify factors associated with increased risk of post-HAART mortality.

Methods: We evaluated baseline (prior to HAART initiation) clinical, demographic and laboratory factors (including CD4+ count and HIV RNA level) for associations with subsequent mortality in 1,600 patients who began HAART in a prospective observational cohort of HIV-infected U.S. military personnel.

Results: Cumulative mortality was 5\%,10\% and $18 \%$ at 4,8 and 12 years post-HAART. Mortality was highest (6.23 deaths/100 person-years [PY]) in those with $\leq 50 \mathrm{CD} 4+$ cells $/ \mathrm{mm}^{3}$ before HAART initiation, and became progressively lower as CD4+ counts increased $\left(0.70 / 100 \mathrm{PY}\right.$ with $\geq 500 \mathrm{CD} 4+$ cells $\left./ \mathrm{mm}^{3}\right)$. In multivariate analysis, factors significantly $(p<0.05)$ associated with post-HAART mortality included: increasing age among those $\geq 40$ years (Hazard ratio [HR] = 1.32 per 5 year increase), clinical AIDS events before HAART $(H R=1.93), \leq 50 \mathrm{CD} 4+$ cells $/ \mathrm{mm}^{3}$ (vs. CD4+ $\geq 500, H R=$ 2.97), greater HIV RNA level $\left(H R=1.36\right.$ per one $\log _{10}$ increase), hepatitis $C$ antibody or chronic hepatitis $B(H R=1.96)$, and HIV diagnosis before $1996(H R=2.44)$. Baseline CD4+ $=51-200$ cells $(H R=1.74, p=0.06)$, and hemoglobin $<12$ $\mathrm{gm} / \mathrm{dL}$ for women or $<13.5$ for men $(H R=1.36, \mathrm{p}=0.07)$ were borderline significant.

Conclusions: Although treatment has improved HIV survival, defining those at greatest risk for death after HAART initiation, including demographic, clinical and laboratory correlates of poorer prognoses, can help identify a subset of patients for whom more intensive monitoring, counseling, and care interventions may improve clinical outcomes and post-HAART survival.
\end{abstract}

Keywords: Highly active antiretroviral therapy, mortality, CD4+ lymphocyte count

\footnotetext{
* Correspondence: lifso001@umn.edu; bagan@idcrp.org

'Division of Epidemiology and Community Health, University of Minnesota, Minneapolis, MN, USA

${ }^{3}$ Infectious Disease Clinical Research Program, Uniformed Services University of Health Sciences, Bethesda, MD, USA

Full list of author information is available at the end of the article
} 


\section{Introduction}

Although highly active antiretroviral therapy (HAART) has significantly reduced mortality in HIV-infected patients [1-3], some patients receiving therapy are still dying. Guidelines for patients on stable HAART recommend laboratory monitoring and follow-up every 3-6 months [4]. However, more frequent and intensive monitoring and care may be indicated for those at greatest risk of post-HAART adverse clinical outcomes. Although CD4+ count is an important determinant of subsequent risk of death, other clinical and laboratory parameters at HAART start, as well as factors such as older age, may also affect post-HAART survival [5-10].

The U.S. Military HIV Natural History Study (NHS) is a prospective observational cohort of consenting HIVinfected military personnel [11]. Although HIV-positive status is an exclusion criterion for enlistment, active duty personnel undergo repeat HIV screening every 1-5 years, allowing for early diagnosis of infection; those found HIV-positive after enlistment receive free HIV specialty care, including HAART, at referral military medical centers. With NHS participants now followed for up to 14 years after HAART initiation, we examined clinical, laboratory and demographic factors at HAART initiation that were associated with subsequent mortality

\section{Methods}

Study cohort: We included active duty members and retirees with: (1) documented HIV serostatus; (2) CD4+ count within six months before HAART; (3) HAART initiation after July 1995, and after or within one month before NHS enrollment. The governing central institutional review board approved this substudy; NHS participants provide written informed consent.

Variables for analysis: We evaluated death reports from participating centers through November 2010. A National Death Index (NDI) match was also conducted to capture deaths through 12/31/06 among participants lost to follow-up. Patients not known to have died who remained under follow-up had follow-up period censored at date of last clinic visit; those lost to follow-up had follow-up censored at 12/31/06 (corresponding to NDI search).

"Baseline" for this analysis was date of HAART initiation. Baseline CD4+ count and HIV RNA level were values closest to HAART initiation in the six months before HAART. Clinical AIDS events were those in the Centers for Disease Control definition (CD4+ criteria excluded) [12]. Anemia was defined as hemoglobin $<12$ $\mathrm{gm} / \mathrm{dL}$ for women and $<13.5 \mathrm{gm} / \mathrm{dL}$ for men within three years before HAART. Body mass index (BMI) calculations used height and weight within one year before or up to 30 days after HAART initiation.
For $80 \%$ of participants with documented last negative and first positive HIV test dates, estimated HIV SC date was calculated as the midpoint. For $20 \%$, date of first positive but not last negative test was available; SC dates were imputed based upon median times between last negative and first positive date for other cohort members with comparable first HIV positive dates [13]. Chronic hepatitis B virus (HBV) infection was defined as $\geq 2$ positive HBV surface antigen tests $\geq 6$ months apart, and hepatitis $\mathrm{C}$ virus (HCV) infection as a positive $\mathrm{HCV}$ antibody test, both determined prior to or within 30 days of HAART initiation. We defined HAART based on regimens with $\geq 2$ ART classes or certain combinations of $\geq 3$ nucleoside/nucleotide reverse transcriptase inhibitors (NRTI); other (non-HAART) ART was essentially mono or dual therapy.

Statistical methods: Mortality rates following HAART initiation were calculated per 100 person-years (PY) with exact Poisson 95\% confidence intervals (CI). We used Kaplan-Meier summaries for cumulative mortality rates post-HAART, and Cox proportional hazards models to estimate associations between baseline covariates and mortality. Based upon visual evaluation of age at HAART start and survival, linear splines were used to model effects of age separately for those $<40$ and $\geq 40$ years of age.

Variables significant $(\mathrm{p}<0.05)$ in univariate analyses were included in the multivariate model. The proportional hazards assumption was assessed by graphical inspection of the log-negative-log of the survival distribution plotted by $\log$ of survival time for covariate categories.

\section{Results}

Characteristics at HAART initiation: Table 1 summarizes characteristics of 1,600 persons in this analysis. Median time from estimated HIV SC to HAART initiation was 4.8 years; median baseline values were: $\mathrm{CD} 4+=$ 326 cells $/ \mathrm{mm}^{3}$, HIV RNA $=4.5 \log _{10}$ copies $/ \mathrm{ml}$, BMI $=$ $25.5 \mathrm{~kg} / \mathrm{m}^{2}$. Six percent were chronically infected with HBV and 5\% HCV antibody positive; $0.5 \%$ had both. Initial HAART regimens were NRTI + protease inhibitor for 59\%, NRTI + non-nucleoside reverse transcriptase inhibitor for $34 \%$, and another regimen for $8 \%$.

Mortality rates: Median follow-up post-HAART was 8.7 years, or 12,486 PY. During follow-up, there were 190 deaths, or 1.52 deaths per 100 PY (95\% CI 1.31, 1.75). Cumulative mortality was $5 \%$ (95\% CI $4 \%-6 \%)$ at 4 years, $10 \%$ (95\% CI $9 \%-12 \%)$ at 8 years, and 18\% (95\% CI $15 \%-20 \%)$ at 12 years. Mortality was highest in those with $\leq 50$ cells $/ \mathrm{mm}^{3}$ prior to HAART, and became progressively lower as CD4+ count increased (Table 1, Figure 1). Mortality rates progressively increased with greater baseline HIV RNA levels and longer time from 
Table 1 Post-HAART Mortality Rate by Demographic, Clinical and Laboratory Parameters Prior to HAART Initiation, U. S. Military HIV Natural History Study

\begin{tabular}{|c|c|c|c|}
\hline & Number and $\%$ of Participants & Number of Deaths & Deaths/100 PY (95\% Cl) \\
\hline \multicolumn{4}{|l|}{ Gender } \\
\hline Male & $1532(96 \%)$ & 182 & $1.53(1.32,1.77)$ \\
\hline Female & $68(4 \%)$ & 8 & $1.37(0.59,2.70)$ \\
\hline \multicolumn{4}{|c|}{ Age at HAART Initiation (years) } \\
\hline$<29$ & $395(25 \%)$ & 27 & $1.11(0.73,1.62)$ \\
\hline $29-33$ & $371(23 \%)$ & 49 & $1.53(1.13,2.02)$ \\
\hline 34-39 & $454(28 \%)$ & 50 & $1.28(0.95,1.69)$ \\
\hline$\geq 40$ & $380(24 \%)$ & 64 & $2.17(1.67,2.77)$ \\
\hline \multicolumn{4}{|l|}{ Race } \\
\hline Caucasian & $712(45 \%)$ & 81 & $1.40(1.12,1.75)$ \\
\hline African American & $686(43 \%)$ & 93 & $1.70(1.38,2.09)$ \\
\hline Other & $202(13 \%)$ & 16 & $1.27(0.72,2.06)$ \\
\hline \multicolumn{4}{|c|}{ BMI at HAART initiation $\left(\mathrm{kg} / \mathrm{m}^{2}\right)$} \\
\hline$<25$ & $642(40 \%)$ & 87 & $1.70(1.36,2.10)$ \\
\hline 25 to $<30$ & $584(37 \%)$ & 54 & $1.23(0.92,1.61)$ \\
\hline$\geq 30$ & $210(13 \%)$ & 16 & $1.07(0.61,1.74)$ \\
\hline Unknown & $164(10 \%)$ & 33 & $2.23(1.54,3.13)$ \\
\hline \multicolumn{4}{|c|}{ Clinical AIDS event prior to HAART } \\
\hline No & $1468(92 \%)$ & 138 & $1.20(1.01,1.42)$ \\
\hline Yes & $132(8 \%)$ & 52 & $5.23(3.90,6.85)$ \\
\hline \multicolumn{4}{|c|}{ CD4+ count at HAART initiation (cells/mm $/ \mathrm{m}^{3}$ ) } \\
\hline$\leq 50$ & $112(7 \%)$ & 53 & $6.23(4.67,8.15)$ \\
\hline $51-200$ & $259(16 \%)$ & 48 & $2.19(1.61,2.90)$ \\
\hline $201-349$ & $517(32 \%)$ & 42 & $1.15(0.83,1.56)$ \\
\hline $350-499$ & $433(27 \%)$ & 30 & $0.89(0.60,1.27)$ \\
\hline$\geq 500$ & $279(17 \%)$ & 17 & $0.70(0.41,1.12)$ \\
\hline \multicolumn{4}{|c|}{ HIV RNA at HAART initiation (copies/ml) } \\
\hline$<1000$ & $139(9 \%)$ & 10 & $0.80(0.38,1.47)$ \\
\hline 1000-9999 & $316(20 \%)$ & 23 & $0.86(0.55,1.29)$ \\
\hline $10,000-99,999$ & $752(47 \%)$ & 79 & $1.38(1.09,1.72)$ \\
\hline$\geq 100,000$ & $393(25 \%)$ & 78 & $2.75(2.18,3.44)$ \\
\hline \multicolumn{4}{|l|}{ Anemia within 3 years } \\
\hline No & $941(59 \%)$ & 60 & $0.87(0.66,1.12)$ \\
\hline Yes & $635(40 \%)$ & 127 & $2.34(1.95,2.79)$ \\
\hline Unknown & $24(2 \%)$ & 3 & $1.96(0.40,5.73)$ \\
\hline \multicolumn{4}{|c|}{ Chronic HBV or HCV antibody positive } \\
\hline No & $1385(87 \%)$ & 138 & $1.29(1.09,1.53)$ \\
\hline Yes & $166(10 \%)$ & 48 & $3.44(2.54,4.56)$ \\
\hline Unknown & $49(3 \%)$ & 4 & $0.95(0.26,2.42)$ \\
\hline \multicolumn{4}{|l|}{ Year of HIV diagnosis } \\
\hline Before 1996 & $848(53 \%)$ & 167 & $2.00(1.71,2.33)$ \\
\hline 1996 or after & $752(47 \%)$ & 23 & $0.56(0.35,0.83)$ \\
\hline \multicolumn{4}{|l|}{ Year of HAART initiation } \\
\hline Before 2000 & $967(60 \%)$ & 171 & $1.74(1.49,2.02)$ \\
\hline $2000-2010$ & $633(40 \%)$ & 19 & $0.72(0.43,1.13)$ \\
\hline
\end{tabular}

Time from SC to HAART initiation (years) 
Table 1 Post-HAART Mortality Rate by Demographic, Clinical and Laboratory Parameters Prior to HAART Initiation, U. S. Military HIV Natural History Study (Continued)

\begin{tabular}{llll}
\hline$<2$ & $473(30 \%)$ & 16 & $0.55(0.31,0.89)$ \\
\hline $2-5$ & $353(22 \%)$ & 31 & $1.20(0.82,1.71)$ \\
\hline 5 to $<9$ & $383(24 \%)$ & 64 & $1.83(1.41,2.33)$ \\
\hline$\geq 9$ & $391(24 \%)$ & 79 & $2.26(1.79,2.82)$ \\
\hline Other (non-HAART) ART & & \\
\hline No & $835(52 \%)$ & 30 & $0.61(0.41,0.87)$ \\
\hline Yes & $765(48 \%)$ & 160 & $2.12(1.80,2.48)$ \\
\hline
\end{tabular}

HIV SC to HAART initiation. Mortality rates by other baseline factors are in Table 1.

Predictors of mortality: In univariate analysis, participants with CD4+ $\leq 50$ cells $/ \mathrm{mm}^{3}$ and $51-200$ cells $/ \mathrm{mm}^{3}$ at HAART initiation had significantly $(\mathrm{p}<0.05)$ increased mortality compared to $\geq 500 \mathrm{CD} 4+$ cells (Table 2). Mortality significantly increased with older age among those $\geq 40$ years, but not among those $<40$ years. Other factors significantly associated with increased mortality included clinical AIDS events before HAART, greater HIV RNA levels, anemia, HCV/chronic HBV, HIV diagnosis before 1996, HAART initiation before 2000, longer time from SC to HAART initiation, and non-HAART ART use (Table 2).

Exploratory analysis found strong colinearity between years from SC to HAART initiation, HIV diagnosis era, era of HAART initiation, and other ART use. For multivariate models, we chose HIV diagnosis before or after
1996, when HAART generally became available. Multivariate factors significantly associated with mortality included: increasing age among those $\geq 40$ years, clinical AIDS event before HAART, CD $4+\leq 50 \mathrm{cells} / \mathrm{mm}^{3}$, greater HIV RNA level, HCV/chronic HBV, and HIV diagnosis before 1996 (Table 2). Anemia within three years prior to HAART $(\mathrm{p}=0.07)$, and CD4+ $=51-200$ cells $/ \mathrm{mm}^{3}$ ( $p=0.06$ ) were of borderline significance.

In additional exploratory analyses, we added gender and race (as potential confounders), or initial HAART regimen class to our multivariate model; none of these was significantly associated with mortality.

\section{Discussion}

Among HIV-infected military personnel, factors at HAART initiation associated with poorer survival included greater age in those $\geq 40$ years, lower CD4+ count, greater HIV RNA level, prior clinical AIDS event,

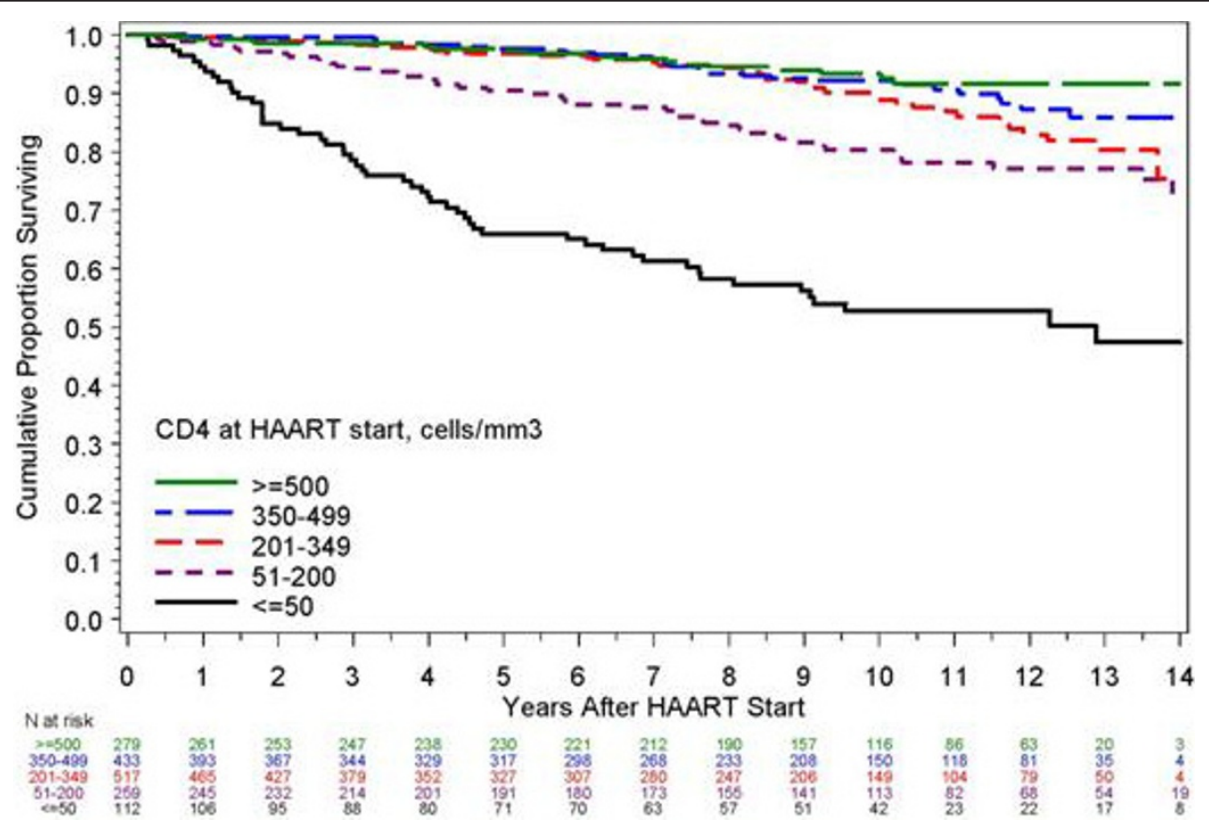

Figure 1 Cumulative Proportion Surviving by Baseline CD4+ Count Prior to HAART Initiation, U.S. Military HIV Natural History Study. 
Table 2 Univariate and Multivariate Model Estimates for Post-HAART Mortality by Baseline Parameters Prior to HAART Initiation, U.S. Military HIV Natural History Study

\begin{tabular}{|c|c|c|}
\hline Baseline Covariate (at HAART initiation) & Univariate Hazard Ratio $(95 \% \mathrm{Cl})$ & Multivariate Hazard Ratio $(95 \% \mathrm{Cl})$ \\
\hline Gender: Female vs. Male & $0.89(0.44,1.80)$ & $-\dagger$ \\
\hline \multicolumn{3}{|l|}{ Age: } \\
\hline per 5 years older if age $<40$ years & $1.11(0.95,1.30)$ & $0.91(0.76,1.08)$ \\
\hline per 5 years older if age $\geq 40$ years & $1.27(1.12,1.44)^{* *}$ & $1.32(1.16,1.51)^{* * *}$ \\
\hline \multicolumn{3}{|l|}{ Race } \\
\hline Caucasian & 1.00 (Reference) & $-\dagger$ \\
\hline African American & $1.22(0.91,1.65)$ & $-\dagger$ \\
\hline Other & $0.92(0.54,1.58)$ & $-\dagger$ \\
\hline \multicolumn{3}{|l|}{ BMI } \\
\hline$<25$ & 1.00 (Reference) & $-\dagger$ \\
\hline 25 to $<30$ & $0.73(0.52,1.03)$ & $-\dagger$ \\
\hline$\geq 30$ & $0.64(0.38,1.10)$ & $-\dagger$ \\
\hline Unknown & $1.29(0.87,1.93)$ & $-\dagger$ \\
\hline Clinical AIDS event prior to HAART & $4.26(3.09,5.87)^{* *}$ & $1.93(1.33,2.81)^{* *}$ \\
\hline \multicolumn{3}{|l|}{ CD4+ count at (cells/mm³) } \\
\hline$\leq 50$ & $8.91(5.15,15.40)^{* *}$ & $2.97(1.56,5.65)^{* * *}$ \\
\hline $51-200$ & $3.07(1.76,5.35)^{* *}$ & $1.74(0.97,3.12)$ \\
\hline 201-349 & $1.69(0.96,2.98)$ & $1.39(0.79,2.46)$ \\
\hline $350-499$ & $1.29(0.71,2.35)$ & $1.21(0.66,2.19)$ \\
\hline$\geq 500$ & 1.00 (Reference) & 1.00 (Reference) \\
\hline HIV RNA (copies/ml) per one $\log _{10}$ increase & $1.72(1.44,2.04)^{* *}$ & $1.36(1.12,1.64)^{*}$ \\
\hline \multicolumn{3}{|l|}{ Anemia within 3 years } \\
\hline No & 1.00 (Reference) & 1.00 (Reference) \\
\hline Yes & $2.61(1.92,3.55)^{* *}$ & $1.36(0.97,1.92)$ \\
\hline Unknown & $2.29(0.72,7.30)$ & $1.96(0.40,5.73)$ \\
\hline \multicolumn{3}{|l|}{ Chronic HBV or HCV antibody positive } \\
\hline No & 1.00 (Reference) & 1.00 (Reference) \\
\hline Yes & $2.61(1.88,3.63)^{* *}$ & $1.96(1.39,2.76)^{* *}$ \\
\hline Unknown & $0.73(0.27,1.99)$ & $0.98(0.36,2.67)$ \\
\hline \multicolumn{3}{|l|}{ Year of HIV diagnosis } \\
\hline Before 1996 & $3.35(2.16,5.21)^{* *}$ & $2.44(1.51,3.93)^{* * *}$ \\
\hline 1996 or after & 1.00 (Reference) & 1.00 (Reference) \\
\hline \multicolumn{3}{|l|}{ Year of HAART initiation } \\
\hline Before 2000 & $2.13(1.31,3.46)^{*}$ & - †十 \\
\hline $2000-2010$ & 1.00 (Reference) & $-+\dagger$ \\
\hline Time from SC to HAART (years) per 1 year increase & $1.10(1.06,1.14)^{* *}$ & $-十+$ \\
\hline Other (non-HAART) ART & $3.28(2.21,4.87)^{* *}$ & $-十 \dagger$ \\
\hline
\end{tabular}

* $\mathrm{p}=0.002 *$ * $\mathrm{p}<0.001$

† Multivariate model included only variables significant in univariate analysis

†† Not included in multivariate model because of strong collinearity with Year of HIV diagnosis

HIV diagnosis before 1996, and either HCV or chronic $\mathrm{HBV}$; in multivariate analysis, anemia was borderline significant.

Consistent with other studies [14-16], mortality rates progressively decreased from lowest to highest baseline CD4+ strata, from 6.23 deaths in $\leq 50 \mathrm{CD} 4+$ cell strata to 0.70 deaths/100 PY in the $\geq 500 \mathrm{CD} 4+$ strata. While we did not find statistically significant mortality differences between higher CD4+ levels [8], this may reflect limited power from smaller numbers of deaths in higher CD4+ categories.

Higher HIV RNA level prior to HAART predicted increased mortality even after adjusting for CD4+ count 
and prior clinical AIDS. One potential explanation is if those with higher HIV RNA levels had longer time to viral suppression after HAART initiation, and/or did not develop viral suppression before death. Ongoing HIV replication may place patients at greater risk of opportunistic disease or death $[17,18]$.

Among those $\geq 40$ years, older age at HAART start was associated with poorer prognosis. Other analyses of HIV patients in the HAART era also report decreased survival with older age $[8-10,18]$. Given increasing recognition of HIV in those $\geq 50$ years $[19,20]$, older patients initiating HIV care and treatment require more intensive monitoring and follow-up.

In this analysis, we combined chronic HBV and HCV antibody positivity, since HIV patients co-infected with either virus have increased mortality from liver-related deaths [21-23]. Although we did not have access to HCV RNA, the great majority of HCV antibody-positive HIV patients likely had chronic HCV infection [23,24]. Providers should know current guidelines for coinfected patient including, when appropriate, therapy against $\mathrm{HBV}$ or $\mathrm{HCV}[4,23,25]$.

This cohort of HIV-infected military personnel has several strengths. Medical and other support provided to participants (including free HIV treatment) minimize socioeconomic disadvantage and lack of access to care that might otherwise influence outcome. Viral suppression rates in this cohort were reported to approach those in clinical trials [11]. The cohort is ethnically diverse. We can estimate time from HIV SC to HAART start. Follow-up extended for some patients to 14 years, longer than many other studies.

Our analysis has several limitations. We focused on baseline factors at HAART initiation, and not timeupdated post-HAART changes. Our endpoint was overall mortality, rather than specific causes of death. Group differences in mortality may be due to additional unmeasured confounding factors. Populations with different demographic or risk characteristics may have different predictors of survival.

In summary, although HAART has improved survival for persons with HIV, defining those at greatest risk for death after HAART initiation, including demographic, clinical and laboratory indicators associated with poorer prognoses, can help identify a subset of patients for whom more intensive monitoring, counseling, and care interventions may improve clinical outcomes and postHAART survival.

\section{Acknowledgements and funding}

Additional members of the Infectious Disease Clinical Research Program HIV/ STI Working Group include Susan Banks, Mary Bavaro, Helen Chun, Cathy Decker, Connor Eggleston, Susan Fraser, Joshua Hartzell, Gunther Hsue, Arthur Johnson, Mark Kortepeter, Tahaniyat Lalani, Michael Landrum,
Michelle Linfesty, Scott Merritt, Robert O'Connell, Sheila Peel, Michael Polis, Roseanne Ressnerk, Edmund Tramont, Tyler Warkentien, Paige Waterman, Amy Weintrob, Timothy Whitman, Glenn Wortmann, and Michael Zapor. The content and views expressed in this publication is the sole responsibility of the authors and does not necessarily reflect the views or policies of the $\mathrm{NIH}$ or the Department of Health and Human Services, the DoD or the Departments of the Army, Navy, Air Force, Department of Defense, nor the U.S. Government. Mention of trade names, commercial products, or organizations does not imply endorsement by the U.S. Government. Support for this work (IDCRP-000-14) was provided by the Infectious Disease Clinical Research Program, a Department of Defense (DoD) program executed through the Uniformed Services University of the Health Sciences. This project has been funded in whole, or in part, with federal funds from the National Institute of Allergy and Infectious Diseases, National Institutes of Health (NIH), under Inter-Agency Agreement Y1-Al-5072.

\section{Author details}

'Division of Epidemiology and Community Health, University of Minnesota, Minneapolis, MN, USA. 'Division of Biostatistics, University of Minnesota, Minneapolis, MN, USA. ${ }^{3}$ Infectious Disease Clinical Research Program, Uniformed Services University of Health Sciences, Bethesda, MD, USA. ${ }^{4}$ Infectious Disease, Naval Medical Center San Diego, San Diego, CA, USA. ${ }^{5}$ Infectious Disease, National Naval Medical Center, Bethesda, MD, USA. ${ }^{6}$ Infectious Disease Service, San Antonio Military Medical Center, San Antonio, TX, USA. ${ }^{7}$ National Institute of Allergy and Infectious Diseases, National Institutes of Health, Bethesda, MD, USA.

\section{Authors' contributions}

AL was lead author on planning and coordinating the analysis, and drafting interim and final versions of the manuscript. EK, PG, AE, and LE provided statistical support and assistance with various aspects of the analysis. GM, $\mathrm{NC}, \mathrm{AG}, \mathrm{JO}, \mathrm{BA}$ had multiple responsibilities related to this cohort, including data collection and oversight at study sites at which participants were followed. Co-authors all provided feedback and offered valuable comments and suggestions on versions of this manuscript. All co-authors have seen and approved the final version of this manuscript.

\section{Competing interests}

The authors declare that they have no competing interests.

Received: 19 September 2011 Accepted: 10 February 2012 Published: 10 February 2012

\section{References}

1. Mocroft A, Ledergerber B, Katlama C, et al: Decline in the AIDS and death rates in the EuroSIDA study: an observational study. Lancet 2003, 362:22-9.

2. Walensky RP, Paltiel AD, Losina E, et al: The survival benefits of AIDS treatment in the United States. J Infect Dis 2006, 194:11-9.

3. Lohse $N$, Hansen AB, Pedersen $G$, et al: Survival of persons with and without HIV infection in Denmark, 1995-2005. Ann Intern Med 2007, 146:87-95.

4. Panel on Antiretroviral Guidelines for Adults and Adolescents: Guidelines for the use of antiretroviral agents in HIV-1-infected adults and adolescents. Dept. Health and Human Services; 2011, 1-167[http://www. aidsinfo.nih.gov/Contentfiles/AdultandAdolescentGL.pdf].

5. Harris RJ, Sterne JA, Abgrall S, et al: Prognostic importance of anaemia in HIV type-1-infected patients starting antiretroviral therapy: collaborative analysis of prospective cohort studies. Antivir Ther 2008, 13:959-67.

6. Moh R, Danel C, Messou E, et al: Incidence and determinants of mortality and morbidity following early antiretroviral therapy initiation in HIVinfected adults in West Africa. AIDS 2007, 21:2483-91.

7. Jaen A, Esteve A, Miro JM, et al: Determinants of HIV progression and assessment of the optimal time to initiate highly active antiretroviral therapy: PISCIS Cohort (Spain). J Acquir Immune Defic Syndr 2008, 47:212-20.

8. Kitahata MM, Gange SJ, Abraham AG, et al: Effect of early versus deferred antiretroviral therapy for HIV on survival. N Engl J Med 2009, 360:1815-26.

9. May M, Boulle A, Phiri S, et al: Prognosis of patients with HIV-1 infection starting antiretroviral therapy in sub-Saharan Africa: a collaborative analysis of scale-up programmes. Lancet 2010, 376:449-57. 
10. Lima VD, Hogg RS, Harrigan PR, et al: Continued improvement in survival among HIV-infected individuals with newer forms of highly active antiretroviral therapy. AIDS 2007, 21:685-92.

11. Marconi VC, Grandits GA, Weintrob AC, et al: Outcomes of highly active antiretroviral therapy in the context of universal access to healthcare: the U.S. Military HIV Natural History Study. AIDS Res Ther 2010, 7:14.

12. Centers for Disease Control: 1993 revised classification system for HIV infection and expanded surveillance case definition for AIDS among adolescents and adults. Morbid Mortal Wkly Rep 1992, 41(RR-17):1-19.

13. Lifson AR, Krantz EM, Eberly LE, et al: Long-term CD4+ lymphocyte response following HAART initiation in a U.S. Military prospective cohort. AIDS Res Ther 2011, 8:2

14. When to Start Consortium: Timing of initiation of antiretroviral therapy in AIDS-free HIV-1-infected patients: a collaborative analysis of 18 HIV cohort studies. Lancet 2009, 373:1352-63.

15. The Antiretroviral Therapy Cohort Collaboration (ART-CC): Prognosis of patients treated with CART from 36 months after initiation, according to current and previous CD4 cell count and plasma HIV-1 RNA measurements. AIDS 2009, 23:2199-208.

16. The HIV-CAUSAL Collaboration: The effect of combined antiretroviral therapy on the overall mortality of HIV-infected individuals. AIDS 2010, 24:123-37.

17. The Strategies for Management of Antiretroviral Therapy (SMART) Study Group: Inferior clinical outcome of the CD4+ cell count-guided antiretroviral treatment interruption strategy in the SMART study: role of CD4+ cell counts and HIV RNA levels during follow-up. J Infect Dis 2008, 197:1145-55.

18. Mugavero MJ, Napravnik S, Cole SR, et al: Viremia copy-years predicts mortality among treatment-naive HIV-infected patients initiating antiretroviral therapy. Clin Infect Dis 2011, 53:927-35.

19. Zhao H, Goetz MB: Complications of HIV infection in an ageing population: challenges in managing older patients on long-term combination antiretroviral therapy. J Antimicrob Chemother 2011, 66:1210-14.

20. Althoff KN, Gebo KA, Gange SJ, et al: CD4 count at presentation for HIV care in the United States and Canada: Are those over 50 years more likely to have a delayed presentation? AIDS Res Ther 2010, 7:45.

21. Weber R, Sabin CA, Friis-Moller N, et al: Liver-related deaths in persons infected with the human immunodeficiency virus: the D:A:D study. Arch Intern Med 2006, 166:1632-41.

22. Smit C, van den Berg C, Geskus R, Berkhout B, Coutinho R, Prins M: Risk of hepatitis-related mortality increased among hepatitis $C$ virus/HIVcoinfected drug users compared with drug users infected only with hepatitis C virus: a 20-year prospective study. J Acquir Immune Defic Syndr 2008, 47:221-5.

23. Thio $C L$ : Hepatitis $B$ and human immunodeficiency virus coinfection. Hepatology 2009, 49(5 Suppl):S138-45.

24. Thomas DL, Astemborski J, Rai RM, et al: The natural history of hepatitis C virus infection: host, viral, and environmental factors. JAMA 2000, 284:450-6.

25. Sulkowski MS, Cheever LW, Spach DH: A guide for evaluation and treatment of hepatitis $C$ in adults coinfected with HIV. U.S. Dept. Health and Human Services, Health Resources and Services Administration; 2011 [http://hab.hrsa.gov/deliverhivaidscare/files/hepccoinfectguide2011.pdf].

doi:10.1186/1742-6405-9-4

Cite this article as: Lifson et al:: Clinical, demographic and laboratory parameters at HAART initiation associated with decreased post-HAART survival in a U.S. military prospective HIV cohort. AIDS Research and

Therapy 2012 9:4.

\section{Submit your next manuscript to BioMed Central and take full advantage of:}

- Convenient online submission

- Thorough peer review

- No space constraints or color figure charges

- Immediate publication on acceptance

- Inclusion in PubMed, CAS, Scopus and Google Scholar

- Research which is freely available for redistribution

Submit your manuscript at www.biomedcentral.com/submit
Biomed Central 